\title{
Erratum to: A short history of the first three years of the Community Genetics Network and its Newsletter
}

\author{
Leo P. ten Kate • Annie Plourde
}

Published online: 12 October 2011

(C) Springer-Verlag 2011

Erratum to: J Community Genet

DOI 10.1007/s12687-011-0049-x

Unfortunately the following acknowledgement has been erroneously omitted:

This project was supported by ECOGENE-21, the Canadian Institutes of Health Research (CIHR team in community genetics (grant \#CTP-82941)). The authors also want to express their gratitude to Drs. D Gaudet and D Brisson, Department of Medicine, Université de Montreal, ECOGENE-21 and Lipid Clinic, Chicoutimi Hospital, Saguenay, QC, Canada, for their support

The online version of the original article can be found at http://dx.doi. org/10.1007/s12687-011-0049-x.

L. P. ten Kate $(\bowtie)$

Department of Clinical Genetics,

VU University Medical Center,

Amsterdam, The Netherlands

e-mail: lp.tenkate@vumc.nl

\section{A. Plourde}

Department of Medicine,

Université de Montréal, ECOGENE-21 and Lipid Clinic,

Chicoutimi Hospital,

Saguenay, QC, Canada 